البصيرة: مجلة الدراسات الإسلامية

AL-BASHIRAH: JOURNAL OF ISLAMIC STUDIES

Vol. 2 No. 2 (2020): 168-185

ISSN: $2807-2170$

Website: https://journal.stiba.ac.id

\title{
نواقض الوضوء عند الشافعية والحنابلة
}

(دراسة مقارنة)

\author{
محمد يسرام \\ المعهد العالي للدراسات الإسلامية واللغة العربية بماكسر

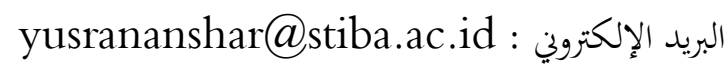 \\ سيف الله بن أنصار

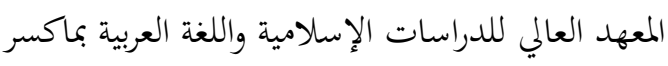

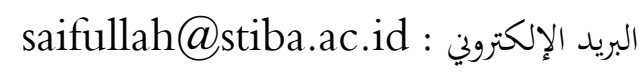 \\ سيناترى \\ المعهد العالي للدراسات الإسلامية واللغة العربية بماكسر \\ sinatra@gmail.com : البريد الإلكترونية
}

المستخلص المقام، وقد

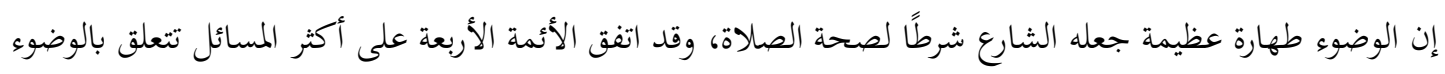

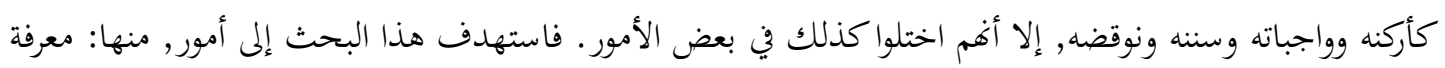

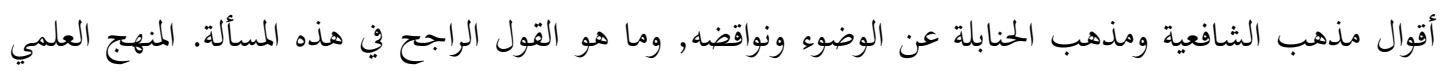

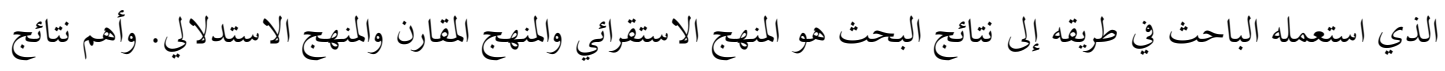

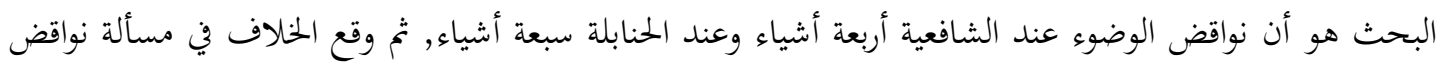

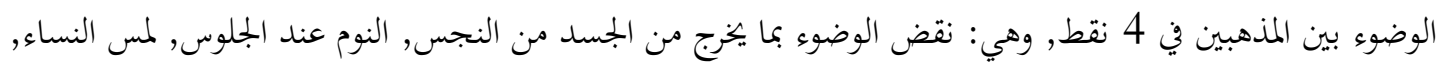

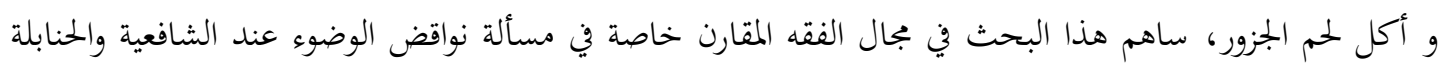
كترقية المعلومات في تلك المسالة. الكلمات الدالة: الحنابلة, الشافعية, المذهب, نواقض, الوضوء. 


\title{
البصيرة: مجلة الاراسات الإسلامية \\ AL-BASHIRAH: JOURNAL OF ISLAMIC STUDIES \\ Vol. 2 No. 2 (2020): 168-185 \\ ISSN: $2807-2170$ \\ Website: https://journal.stiba.ac.id

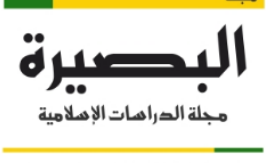 \\ AL-BASHIRAH \\ JOURNAL OF ISLAMIC STUDIES \\ NULLIFIERS OF ABLUTION ACCORDING TO THE PERSPECTIVE OF SHAFI'I SCHOOL AND HANBALI SCHOOL (COMPARATIVE STUDY)
}

\author{
Muhammad Yusram \\ Sekolah Tinggi Ilmu Islam dan Bahasa Arab (STIBA) Makassar, Indonesia \\ Email : yusrananshar@stiba.ac.id \\ Saifullah bin Anshor \\ Sekolah Tinggi Ilmu Islam dan Bahasa Arab (STIBA) Makassar, Indonesia \\ Email : saifullah@stiba.ac.id

\section{Sinatra} \\ Sekolah Tinggi Ilmu Islam dan Bahasa Arab (STIBA) Makassar, Indonesia \\ Email : sinatra@gmail.com
}

\begin{abstract}
Ablution is a great form of taharah so Sharia makes it a legal condition of prayer. The four schools have agreed on most problems related to ablution, such as its pillars, its obligations, its circumcision and its nullifiers, but they are also different in some ways. This study aims to find out the opinions of Shafi'i and Hanbali schools about ablution and things which invalidate it, as well as strong opinions of both. The scientific methods used to achieve results are inductive-deductive and comparison methods. The results showed that the things which invalidate it according to the Shafi'i school there are four things and according to the Hanbali school there are seven. Then there is the difference of opinion between the two schools in this matter on four points, namely: the feces coming out of the body as thing can invalidate the ablution, sleeping while sitting, touching women and eating camel meat. This research is expected to contribute in the field of comparative jurisprudence of schools, especially in the problem of nullifiers of ablution according to Shafi'i and Hanbali schools, and increasing knowledge in this matter.
\end{abstract}

Keywords: Hanabilah, Shafi'iyah, school, taharah, nullifiers of ablotion.

ولقد شثمل الفقه الإسلامي كل نواحي الحياة الفردية والجماعية من شؤون اقتصادية واجتماعية

وسياسية وغيرها إبان عز الدولة الإسلامية، حيث قام الفقهاء المجتهدون من الصحابة والتابعين ومن

بعدهم بدراسة كل ما يعترض حياة الناس من مسائل وقضايا، على ضوء أصول الشريعة وقواعدها، وبينوا

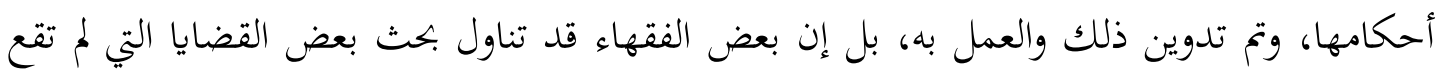

بعدُ، وإنما بناء على افتراضات، وقد عده بعض الناس ترفًا فقهيًا. وذلك يرجع إلى أفمم قد قاموا ببيان 
البصيرة: مجلة الاراسات الإسلامية

AL-BASHIRAH: JOURNAL OF ISLAMIC STUDIES

Vol. 2 No. 2 (2020): 168-185

ISSN: $2807-2170$

Website: https://journal.stiba.ac.id

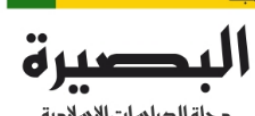

مجلة الصراهات الإصلامية

AL-BASHIRAH

الأحكام في النوازل والوقائع في عصرهم، وتحاوزوها إلى غيرها، وقد تمت الاستفادة منها في العصور التالية

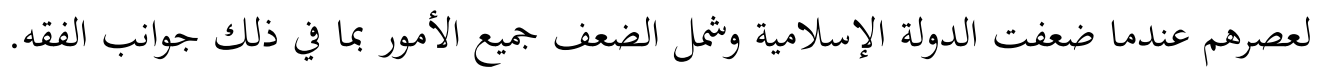

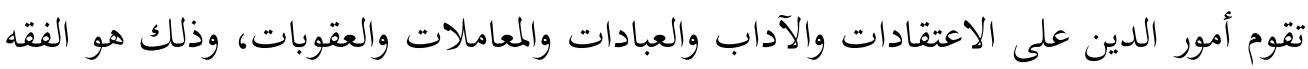
الأكبر، وبما أن بحثنا في فقه الأحكام الشرعية العملية، فلا نتعرض لبحث أمور العقيدة والأخلاق.

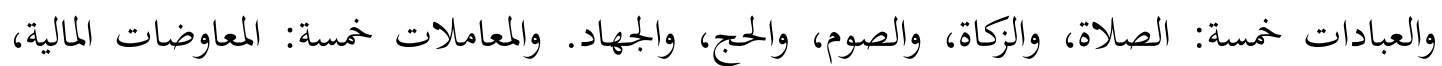
والمناكحات، والمخاصمات، والأمانات، والتركات. والعقوبات خمسة: القصاص، وحد السرقة، والزنا، والقذف، والردة.

والعبادة: هي اسم جامع لكل ما يحبه الله ويرضاه من الأقوال، والأعمال الباطنة والظاهرة. ودين

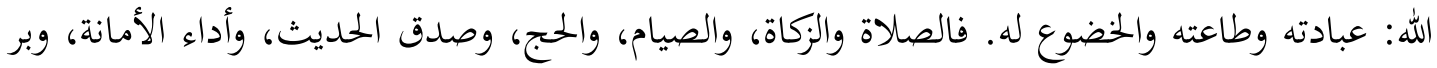

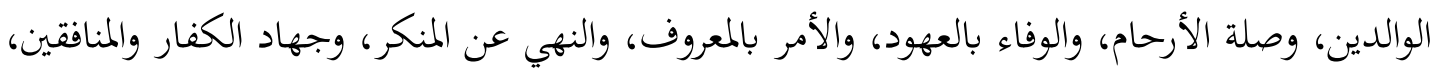

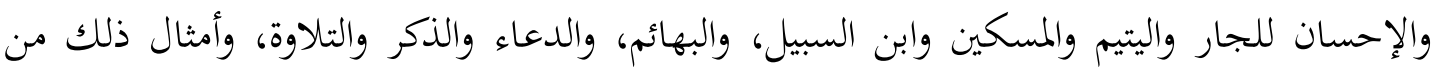

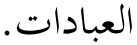

وكذلك حب الله ورسوله، وخشية الله والإنابة إليه، وإخلاص الدين له، والصبر لحكمه، والشكر لنعمه، والرضا بقضائه، والتوكل عليه، والرجاء لرمته، والخوف من عذابه، وأمثال ذلك، هي من العبادة،

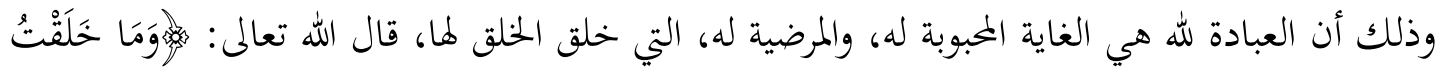

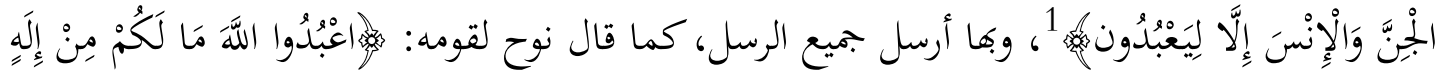

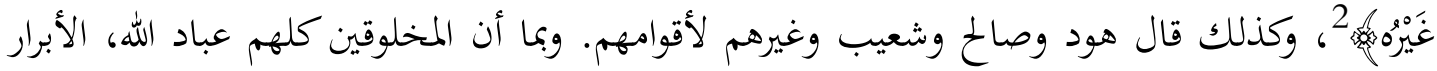
منهم والفجار، والمؤمنون والكفار، وأهل الجنة وأهل النار، فإن عبوديتهم الحقة تستلزم عبادة الله الواحد

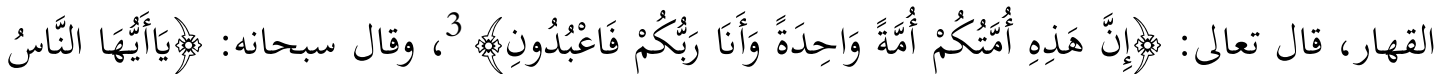

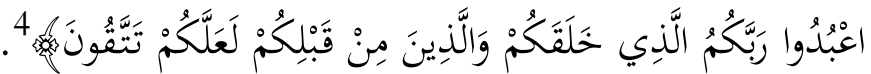

$$
\begin{aligned}
& \text { 1. سورة الذاريات : } 56 \\
& \text { 2. سورة الأعراف: } 59 \\
& \text { 3. سورة الأنبياء : } 92 \\
& \text { 21: سورة البقرة }
\end{aligned}
$$




\section{البصيرة: مجلة الار اسنات الإسلامية \\ AL-BASHIRAH: JOURNAL OF ISLAMIC STUDIES \\ Vol. 2 No. 2 (2020): 168-185 \\ ISSN: $2807-2170$ \\ Website: https://journal.stiba.ac.id

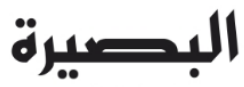 \\ مجلة الصراعات الإصلامية \\ AL-BASHIRAH}

تعدّ الطهارة من الأمور المهمّة في الإسلام، فهي شرط لصحّة بعض العبادات التي يتقرّب بها العبد إلى الله تعالى؛ فهي شرط لصحّة الصلاة، وصحّة الطواف عند كثير من العلماء، ومّّا يدلّ على أها شرط لصحة الصلاة ما رواه الصحابيّ أبو هريرة رضي الله عنه، حيث قال عن رسول الله صلّى الله عليه

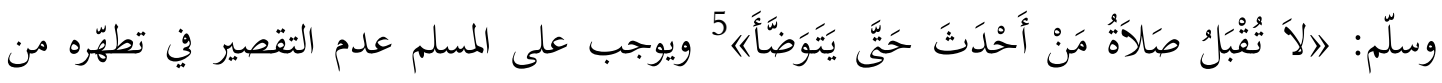

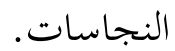

فذلك من أسباب تعذيب العبد في القبر حيث روى الإمام البخاريّ في صحيحه عن عبد الله

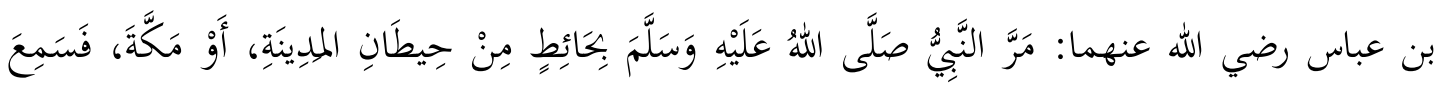

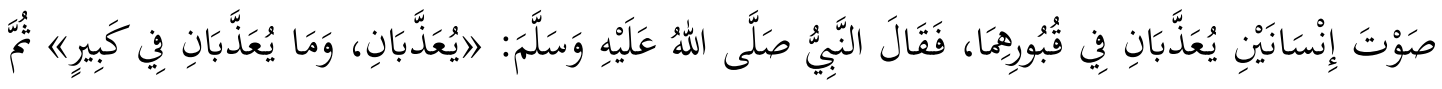

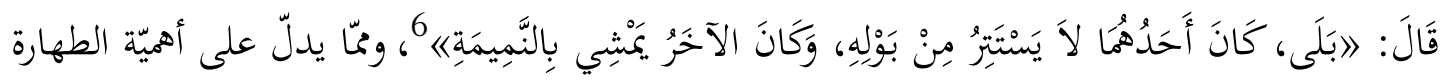

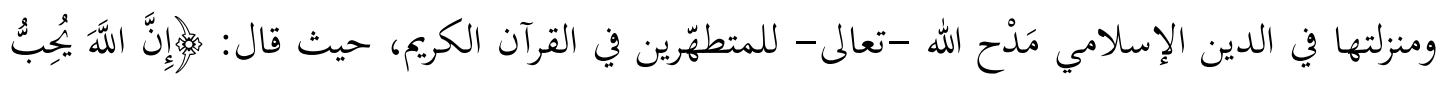

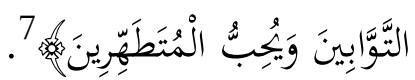

ومّّا يدلّ أيضاً على أهميتها وَصْف النبيّ -صلّى الله عليه وسلّم - لها بأفّها نصف الإيمان، فالطهارة موافقة للفطرة التي فطر الله تعالى الناس عليها، فالإنسان بطبيعته بجبول على حبّ النظافة والجمال والنفور من النجاسة، فدين الإسلام دين الفطرة، والطهارة والنظافة تحميان المرء من أمراض كثيرة، فالقذارة والنجاسة سببان في حصول كثير من الأمراض.

عند مذهب الشافعية نواقض الوضوء، هي: الأول: الخارج من أحد السبيلين إلا المني أي مني الشخص نفسه، لأنه أوجب الغسل. الثاني: زوال العقل بجنون أو إغماء أو نوم إلا النوم قاعداً مُكِنّاً مقعده من مقره كالأرض، وظهر دابة سائرة، وإن كان مستنداً إلى شيء بحيث لو زال، لسقط. الثالث: 5. كواه البخاري في كتاب الوضوء من صحيحه؛ باب لا تقبل صلاة بغير طهور، رقم(135)، ومسلم في كتاب الطهارة من صحيحه؛ باب وجوب الطهارة للصلاة، رقم(225). 6. رواه البخاري في كتاب الوضوء من صحيحه، باب من الكبائر أن لا يستتر من بوله، رقم(216).

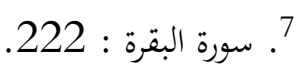


التقاء بشرتي الرجل والمرأة ولو ميتة، عمداً أو سهواً. وينتقض اللامس والملموس، ولا ينقض صغير أو

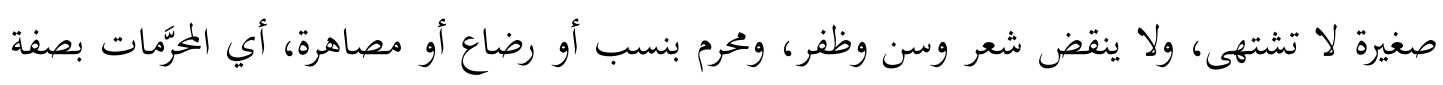

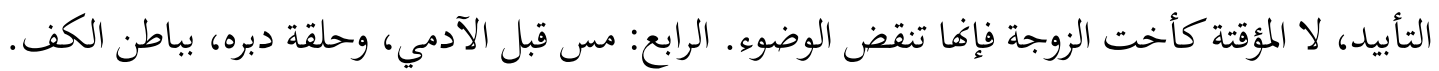

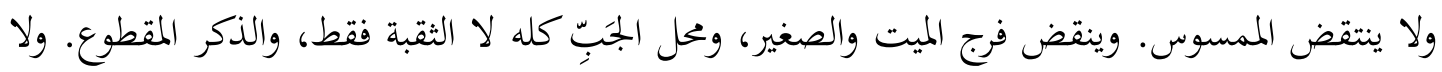
ينقض فرج البهيمة، ولا المس برأس الأصابع وما بينها.

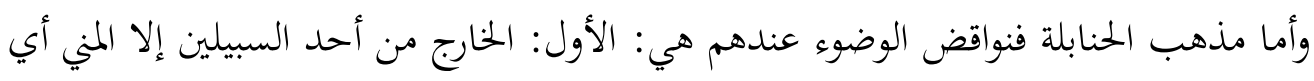

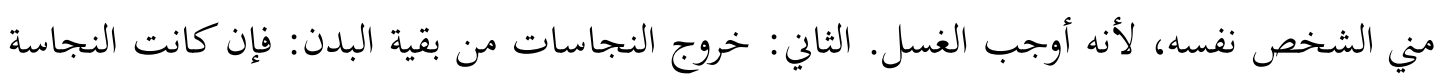

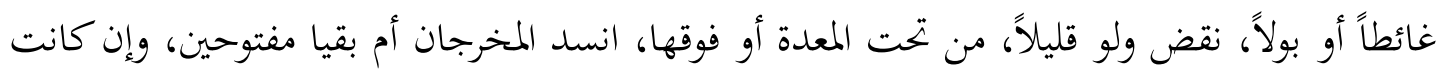

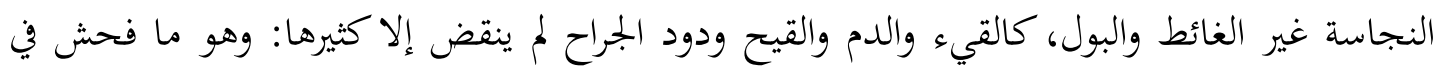

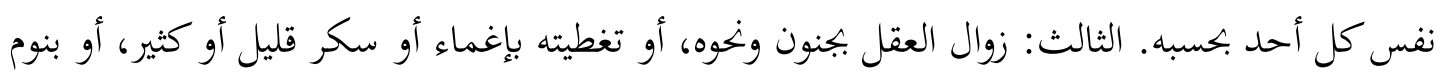

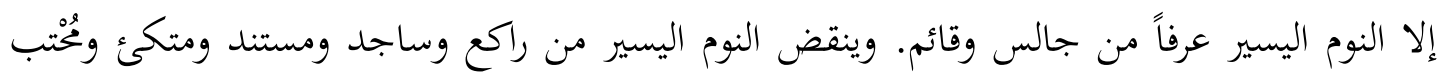

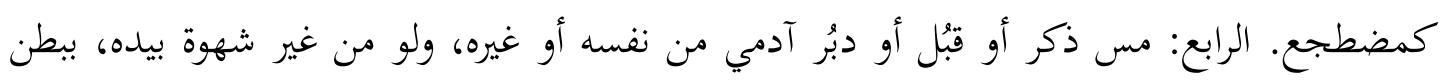

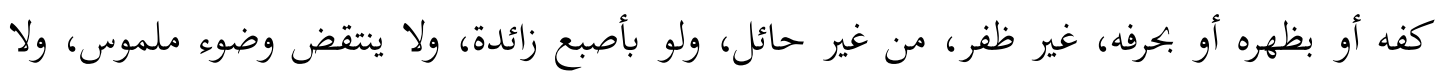

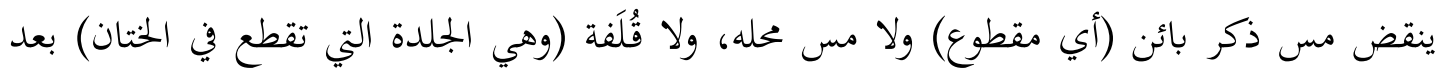

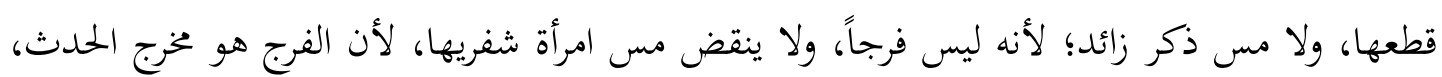

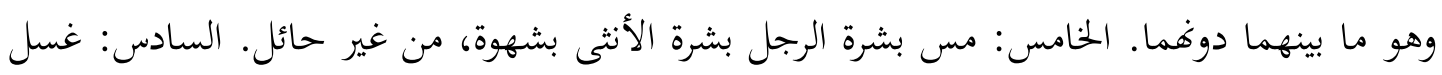

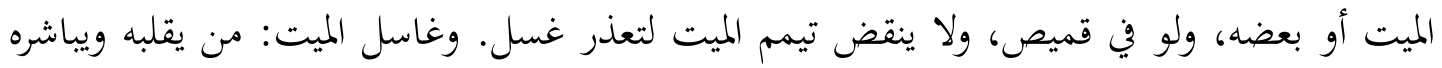

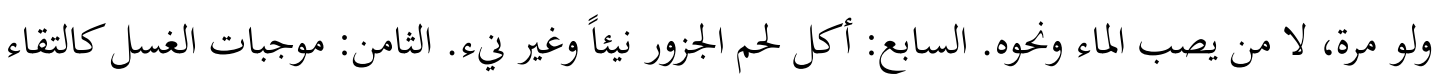
المتانين وانتقال المني وإسلام الكافر الأصلي أو المرتد.

استهدف هذا البحث إلى أمور، منها: فهم الوضوء والأحكام المتعلقة به عند مذهب الشافعية المناف

ومذهب الحنابلة، وفهم أقوال مذهب الشافعية ومذهب الحنابلة عن الوضوء ونواقضه، وفهم سبب الخلاف بين الشافعية والحنابلة في نواقض الوضوء، وما هو القول الراجح في هذه المسألة. وحتى لا يخزج هذا البحث من الموضوع فحدد الباحث لبحثه النقاط الآتية:

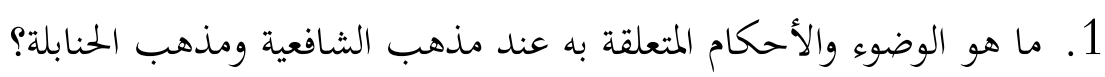
2. ما هي أقوال مذهب الشافعية ومذهب الحنابلة عن الوضوء ونواقضه ؟ 
البصيرة: مجلة الداسات الإسلامية

AL-BASHIRAH: JOURNAL OF ISLAMIC STUDIES

Vol. 2 No. 2 (2020): 168-185

ISSN: $2807-2170$

Website: https://journal.stiba.ac.id

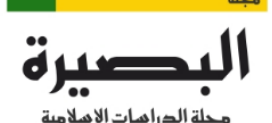

مجلة الصراسات الإصلامية

AL-BASHIRAH

$$
\text { 3. 3. ما سبب الخلاف بين الشافعية والحنابلة في نواقض الوضوء ؟ }
$$

حسب تطلع الباحث على الدراسات السابقة المتعلقة بموضوع البحث، فلم يجد إلا موضوعًا

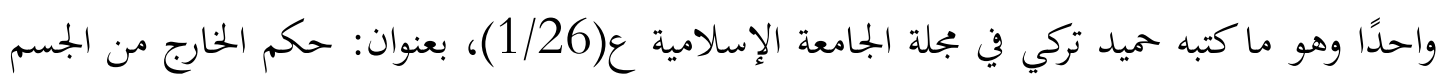

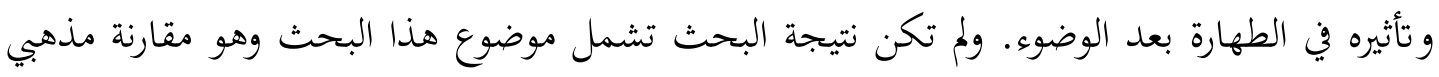

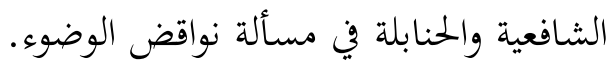

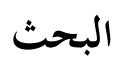

الوضوء ونواقضه عند مذهب الشافعية ومذهب الحنابلة

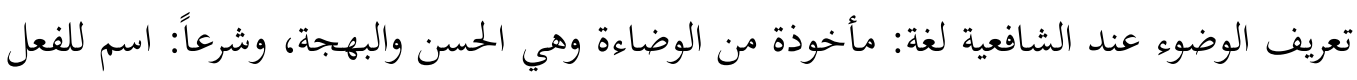

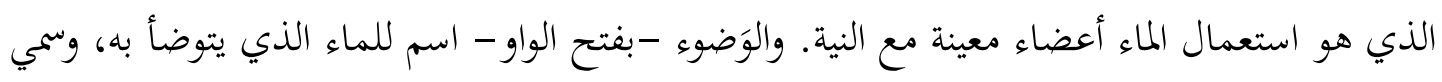
بذلك لما يضيف على الأعضاء من وضاءة بغسلها وتنظيفها. 8

$$
\text { ونواقض الوضوء عند الشافعية على النحو التالي: }
$$

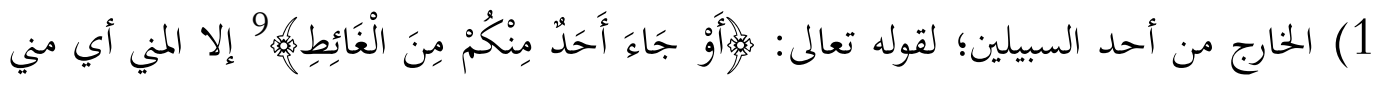

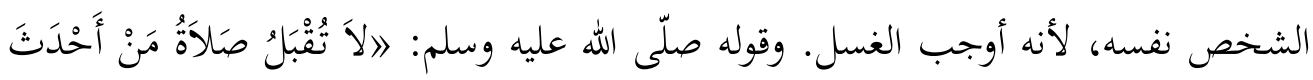

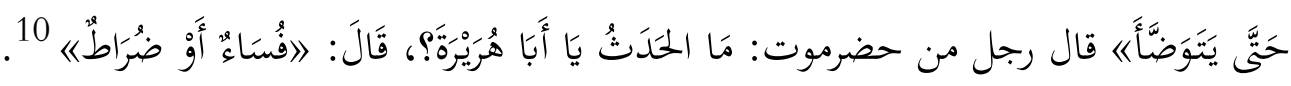

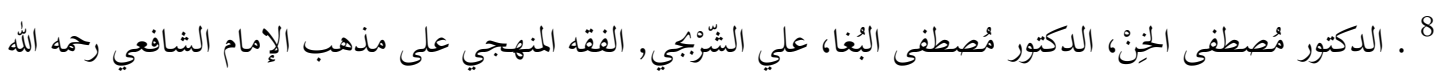

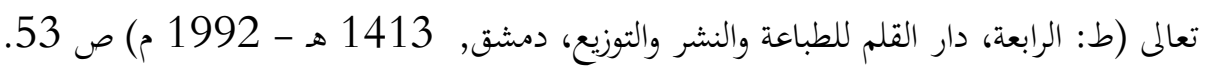
9.

10. . رواه البخاري في كتاب الوضوء من صحيحه؛ باب لا تقبل صلاة بغير طهور، رقم(135)، ومسلم في كتاب الطهارة من صحيحه؛ باب وجوب الطهارة للصلاة، رقم(225). 


\section{البصيرة: مجلة الاراسات الإسلامية \\ AL-BASHIRAH: JOURNAL OF ISLAMIC STUDIES \\ Vol. 2 No. 2 (2020): 168-185 \\ ISSN: $2807-2170$ \\ Website: https://journal.stiba.ac.id

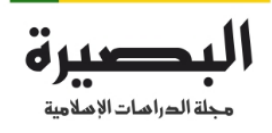 \\ AL-BASHIRAH

2) زوال العقل بجنون أو إغماء أو نوم إلا النوم قاعداً ممكِنِاً مقعده من مقره كالأرض، وظهر دابة سائرة، وإن كان مستنداً إلى شيء بحيث لو زال لسقط، لقوله صلّى الله عليه وسلم من حديث

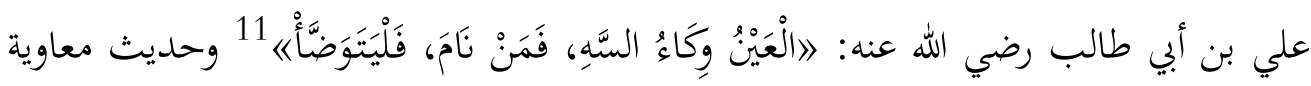

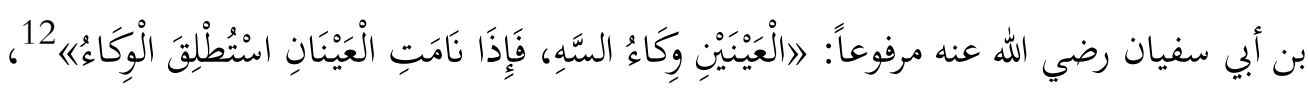
والحديثان يدلان على أن النوم مظِنَّة للنقض، لا أنه بنفسه ناقض.

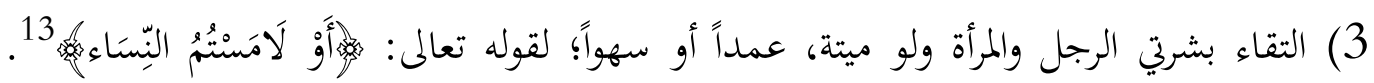
وينتقض اللامس والملموس، ولا ينقض صغير أو صغيرة لا تشتهى، ولا ينقض شعر وسن وظفر، ومحرم بنسب أو رضاع أو مصاهرة، أي المحرَّمات بصفة التأبيد، لا المؤقتة كأخت الزوجة فإها تنقض الوضوء.

4) مس قبل الآدمي، وحلقة دبره، بباطن الكف؛ لقوله صلّى الله عليه وسلم: المَنْ مَسَّ ذَكَرَه،

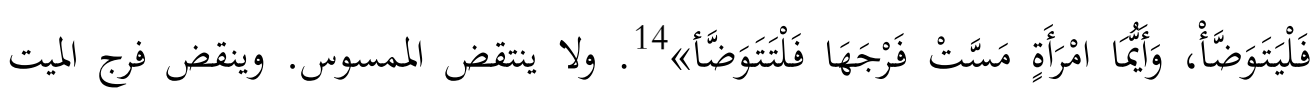
والصغير، ومحل الجَبِّ كله لا الثقبة فقط، والذكر المقطوع. ولا ينقض فرج البهيمة، ولا المس برأس الأصابع وما بينها. وأما تعريف الوضوء عند الحنابلة لغة: الحسن والنظافة، وفي الاصطلاح: استعمال الماء في أعضاء خصوصة بكيفية مخصوصة.15.

11. رواه أبو داود في كتاب الطهارة من سننه؛ باب في الوضوء من النوم، رقم(203)، وابن ماجه في كتاب الطهارة

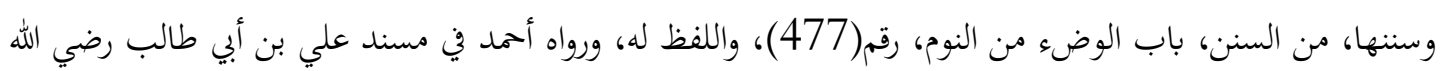
عنه من المسند، رقم(887).

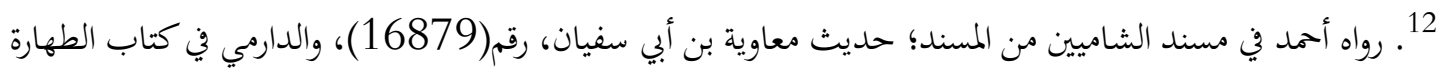
من سننه؛ باب الوضوء من النوم، رقم(749). 13. سورة المائدة: 14. رواه أحمد في مسند عبد الله بن عمرو من المسند؛ رقم(7076).

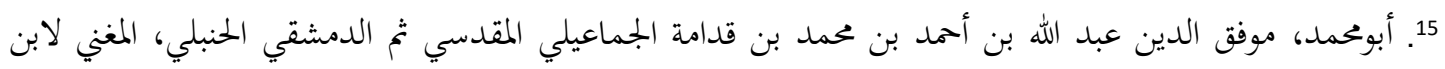

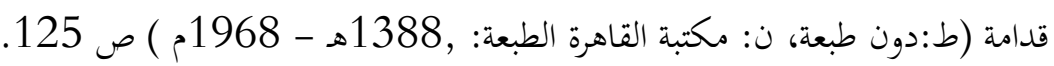


البصيرة: مجلة الاراسات الإسلامية

AL-BASHIRAH: JOURNAL OF ISLAMIC STUDIES

Vol. 2 No. 2 (2020): 168-185

ISSN: $2807-2170$

Website: https://journal.stiba.ac.id

البحصيرة

مجلة الصراهات الإصلامية

AL-BASHIRAH

ونواقضه عند الحنابلة ثمانية أنواع، وهي كالتالي:

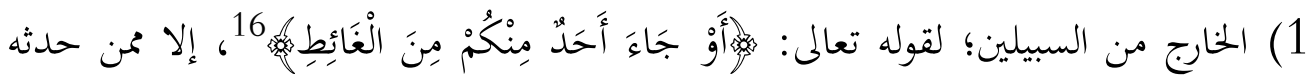

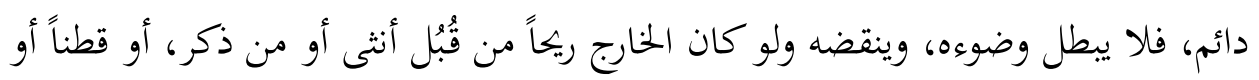

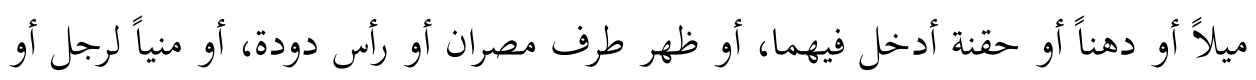
امرأة استدخلته امرأة في فرجها ثم خرج.

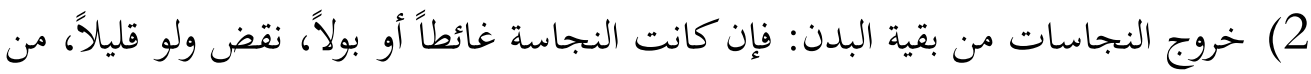

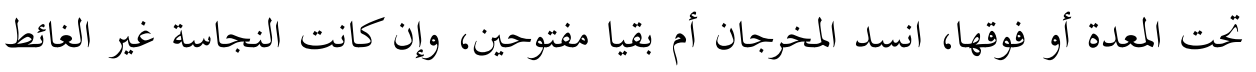

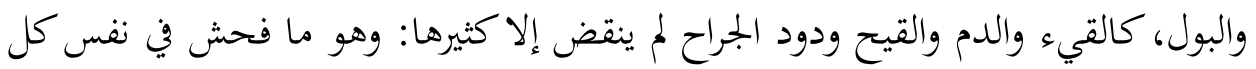

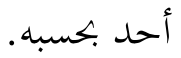

3) زوال العقل بجنون ونخوه؛ لقوله صلّى الله عليه وسلم في حديث علي بن أبي طالب رضي

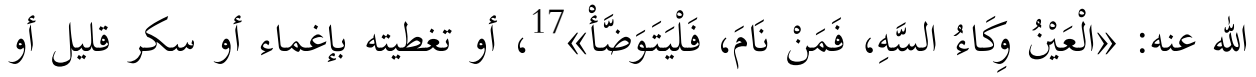

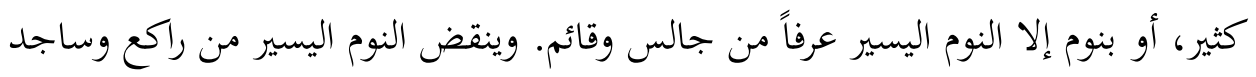

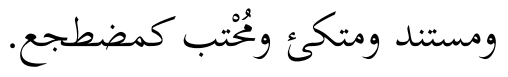

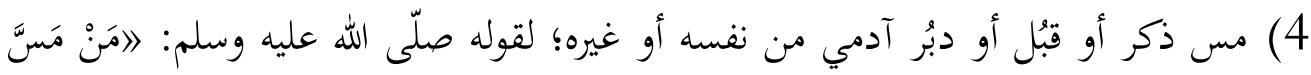

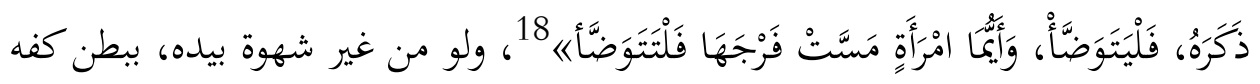

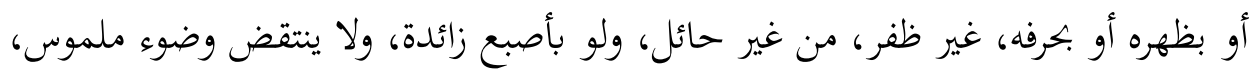

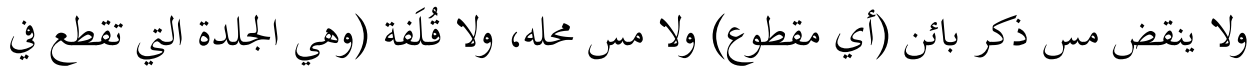

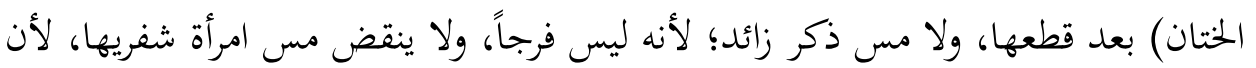

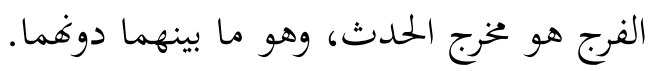

6: 6

17. رواه أبو داود في كتاب الطهارة من سننه؛ باب في الوضوء من النوم، رقم(203)، وابن ماجه في كتاب الطهارة وسننها، من السنن، باب الوضء من النوم، رقم(477)، واللفظ له، ورواه أحمد في مسند علي بن أبي طالب رضي رضي الله

عنه من المسند، رقم(887) 18 ـ رواه أحمد في مسند عبد الله بن عمرو، مرو من المسند؛ رقم(7076). 
5) مس بشرة الرجل بشرة الأنثى بشهوة، من غير حائل. ولا ينقض مس طفلة وطفل من دون

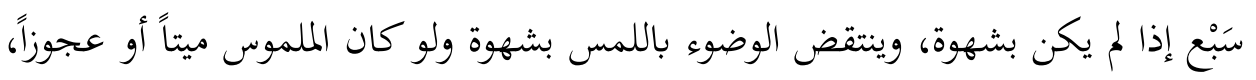

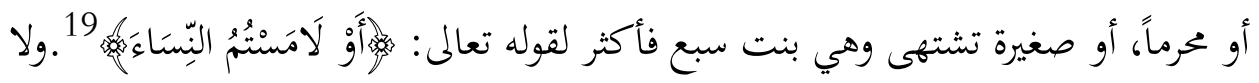

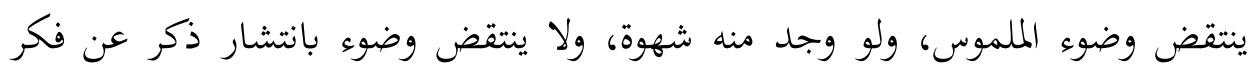

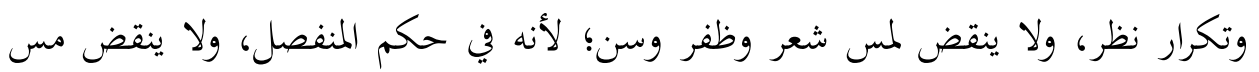
عضو مقطوع لزوال حرمته، ولا مس أمرد ولو بشهوة، لعدم تناول الآية له، ولأنه ليس محلاً

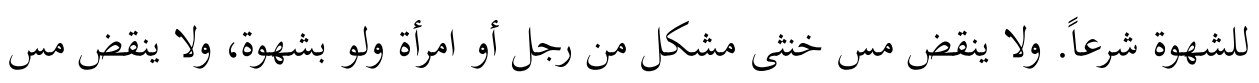
الرجل الرجل، ولا المرأة المرأة، ولو بشهوة فيهن. 6) غسل الميت أو بعضه ، ولو في قميص، ولا ينقض تيمم الميت لتعذر غسل. ولمرة وغاسل الميت: من يقلبه ويباشره ولو مرة، لا من يصب الماء ونهوه.

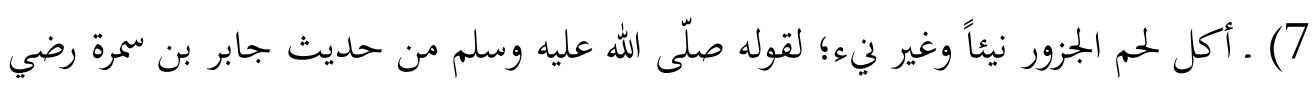

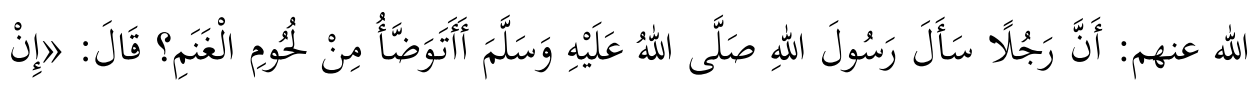

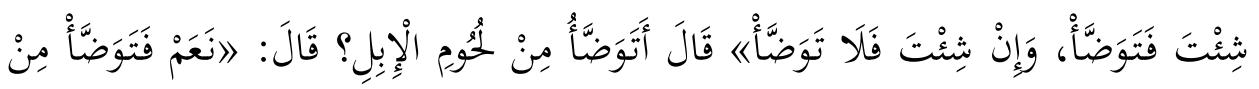

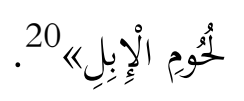

8) موجبات الغسل كالتقاء الحتّانين وانتقال المني وإسلام الكافر الأصلي أو المرتد؛ لما جاء عَنْ

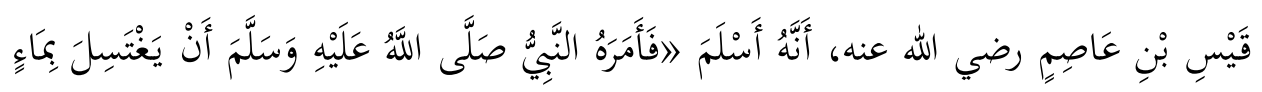

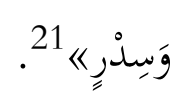

سبب الخلاف بين الشافعية والحنابلة في نواقض الوضوء

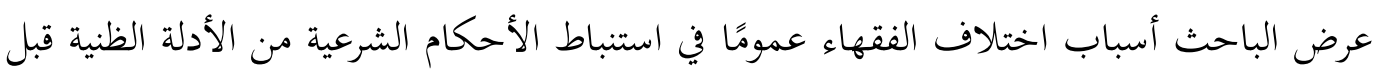
عرض الخلاف بين مذهبي الشافعية والحنابلة، وهي كما تأتي: 19 20 م ـ رواه مسلم في كتاب الحيض من صحيحه؛ باب الوضوء من لخوم الإبل، رقم(360)

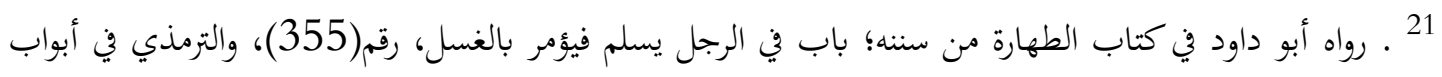

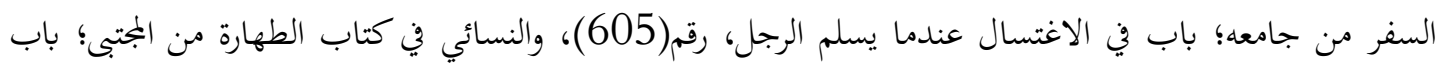

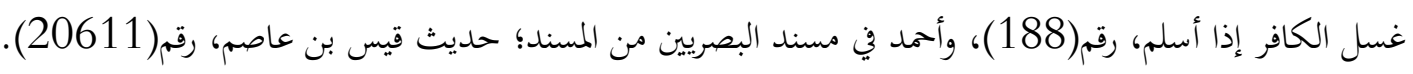


1) اختلاف معاني الألفاظ العربية: إما بسبب كون اللفظ مجملاً، أو مشتركاً، أو متردداً بين العموم والخصوص، أو بين الحقيقة والمجاز، أو بين الحقيقة والعرف، أو بسبب إطلاق اللفظ تارة وتقييده

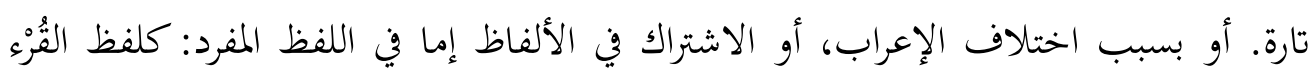
الذي يطلق على الأطهار وعلى الحيضات، ولفظ الأمر: هل يحمل على الوجوب أو على الندب، ولفظ النهي: هل يحمل على التحريم أو الكراهية؟ وإما في اللفظ المركب: مثل قوله تعالى

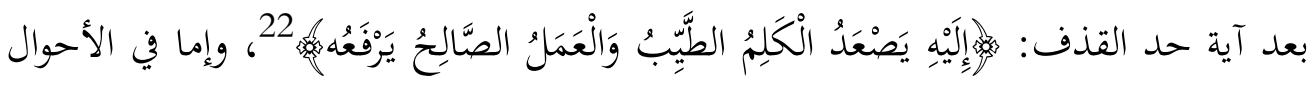

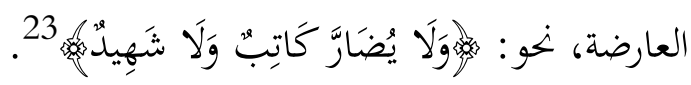

2) اختلاف الرواية: وله أسباب ثمانية، كأن يصل الحديث إلى أحدهم ولايصل إلى غيره، أو يصل من طريق ضعيف لاييتج به، ويصل إلى آخر من طريق صحيح، أو يصل من طريق واحد، ويرى أحدهم أن في بعض رواته ضعفاً لايعتقده غيره، أو لايراه مانعاً من قبول الرواية، وهذا مبني على صنى إنى الاختلاف في طريق التعديل والترجيح. أو يصل إليهما من طريق متفق عليه، غير أن أحدهما يشترط في العمل به شروطاً لا يشترطها الآخر، كالحديث المرسل (وهو مارواه غير الصحابي

$$
\text { بدون سند إلى الرسول صلّى الله عليه وسلم). }
$$

3) اختلاف المصادر: وهناك أدلة اختلفوا في مدى الاعتماد عليها، كالاستحسان والمصالح المرسلة

$$
\text { وقول الصحابي والاستصحاب، والذرائع ونهوها من دعوى البراءة أو الإباحة وعدمها. }
$$

4) اختلاف القواعد الأصولية أحياناً: كقاعدة العام المخصوص ليس بحجة، والمفهوم ليس بحجة،

$$
\text { والزيادة على النص القرآني نسخ أم لا، ونحو ذلك. }
$$

5) الاجتهاد بالقياس: هو أوسع الأسباب اختلافاً، فإن له أصلاً وشروطاً وعلة، وللعلة شروطاً ومسالك، وين كل ذلك بجال للاختلاف، والاتفاق بالذات على أصل القياس ومايجري فيه الاجتهاد ومالايجري أمر يكاد يكون غير متحقق. كما أن تحقيق المناط (وهو التحقق من وجود

$$
\text { العلة في الفرع) من أهم أسباب اختلاف الفقهاء. }
$$

6) التعارض والترجيح بين الأدلة: وهو باب واسع اختلفت فيه الأنظار وكثر فيه الجدل. وهو يتناول دعوى التأويل والتعليل والجمع والتوفيق والنسخ وعدمه. والتعارض إما بين النصوص أو بين الأقيسة مع بعضها، والتعارض في السنة قد يكون في الأقوال أو في الأفعال، أو في الإقرارات، 
البصيرة: مجلة الاراسات الإسلامية

AL-BASHIRAH: JOURNAL OF ISLAMIC STUDIES

Vol. 2 No. 2 (2020): 168-185

ISSN: $2807-2170$

Website: https://journal.stiba.ac.id

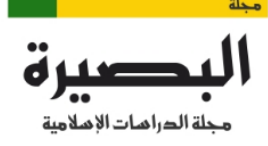

AL-BASHIRAH

وقد يكون الاختلاف بسبب وصف تصرف الرسول سياسة أو إفتاء، ويزال التعارض بأسباب

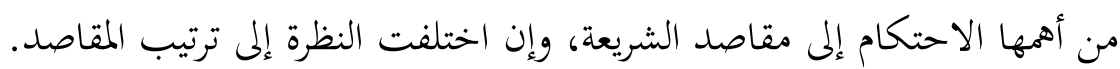

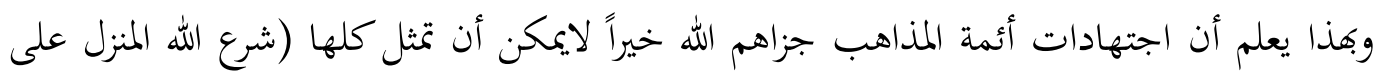

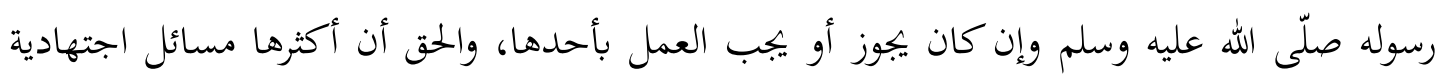

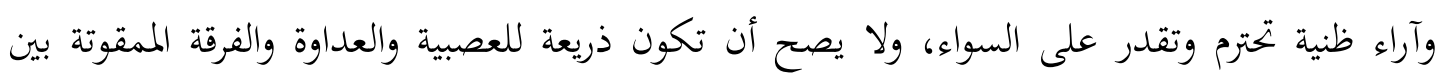

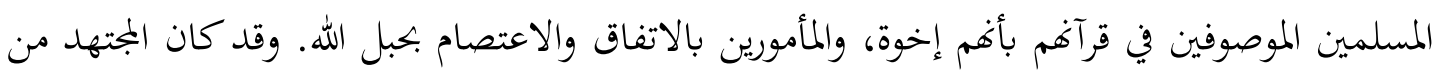

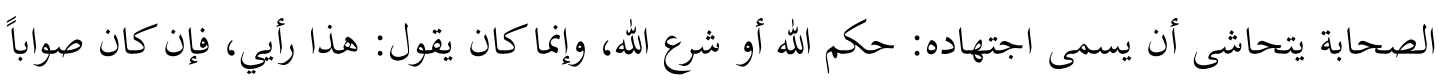

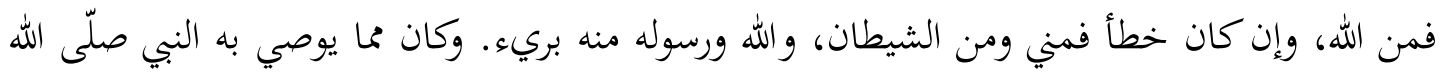

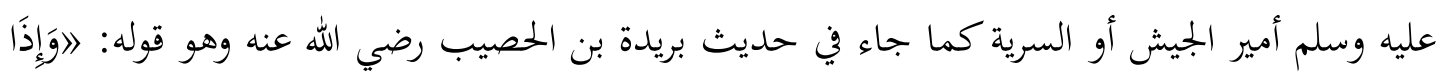

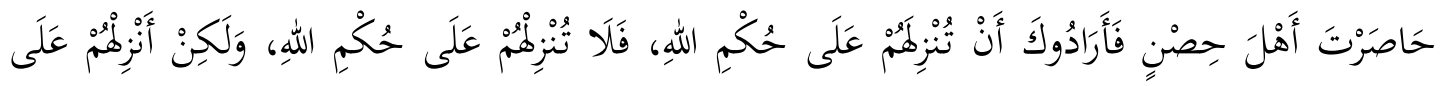

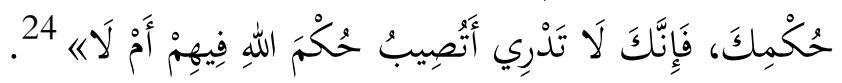
نواقض الوضوء التي اختلف فيها بين الثافعية والحنابلة كما يلي:

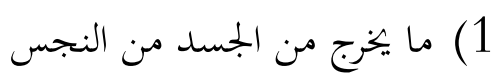

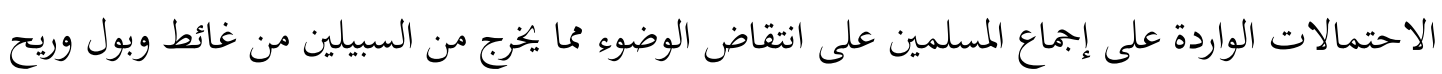

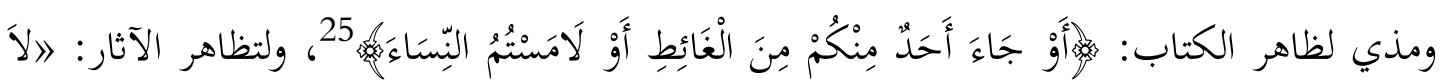

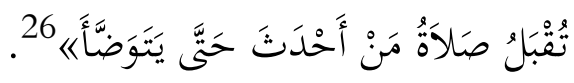

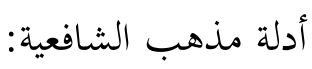

- المعتبر المخرجان، لأن حكم نقض الطهارة معلق بكما، من باب الخاص أريد به العام،

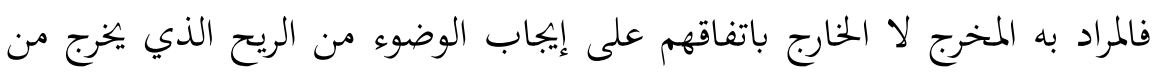

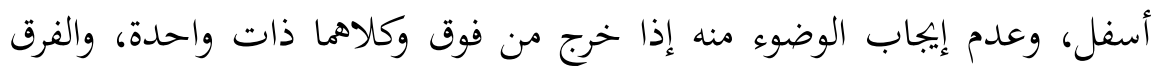

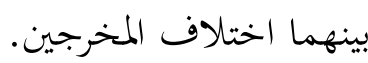

24.2 رواه مسلم في كتاب الجهاد والسير من صحيحه؛ باب تأمير الإمام الأمراء على البعوث، رقم(1731). 25. سورة النساء: 43.

66. رواه البخاري في كتاب الوضوء من صحيحه؛ باب لا تقبل صلاة بغير طهور، رقم(135)، ومسلم في كتاب الطهارة من صحيحه؛ باب وجوب الطهارة للصلاة، رقم(225). 


\section{البصيرة: مجلة الاراسات الإسلامية \\ AL-BASHIRAH: JOURNAL OF ISLAMIC STUDIES \\ Vol. 2 No. 2 (2020): 168-185 \\ ISSN: $2807-2170$ \\ Website: https://journal.stiba.ac.id

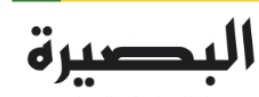 \\ مجلة الصراهات الإسلامية \\ AL-BASHIRAH}

- أمره النبي صلّى الله عليه وسلم المستحاضة بالوضوء لكل الصلاة، والاستحاضة

مرض.

أدلة مذهب الحنابلة

- بأن المقصود بذلك هو الخارج النجس لكون النجاسة مؤثرة في الطهارة، وهذه الطهارة

وإن كانت طهارة حكمية فإن فيها شبها من الطهارة المعنوية (نعني: طهارة النجس)

- مبحديث أبي الدرداء رضي الله عنه: الَأنَّ رَسُولَ اللهِ صَلَّى اللهُ عَلَيْهِه وَسَلَّمَ قَاءَ،

فَتَوَضََّأَنا 27.

- وبما روي عن ابن عمر -رضي الله عنهما- وغيره من إيجابهم الوضوء من الرعاف 28.

- وبما روي من أمره - صلى الله عليه وسلم - المستحاضة بالوضوء لكل صلاة، وقوله:

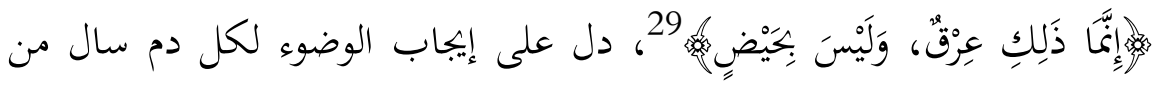

ثمرة الخلاف

- مذهب الشافعية: لا ينتقض وضوء من قاء أو رعف، وينتقض إذا خرج من أحد

سبيليه حصا أو نحوه.

- مذهب الحنابلة: ينتقض وضوء من قاء أو رعف، ولا ينتقض إذا خرج من أحد

سبيليه حصا أو نهوه.

2) انتقاض الوضوء بالنوم جالسا

27. رواه أبو داود في كتاب الصوم من سننه؛ باب الصائم يستقيء عامداً، رقم(2381)، والترمذي في أبواب الطهارة

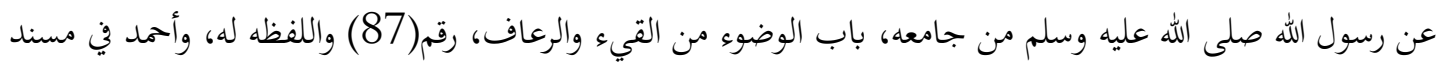

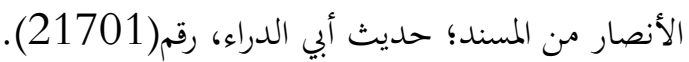

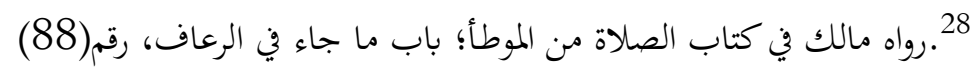

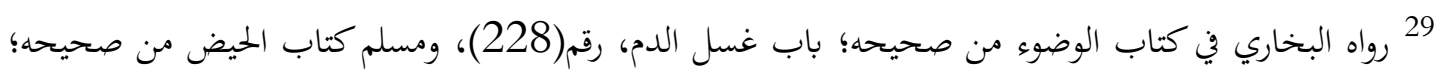

باب المستحاضة وغسلها وصلاقا، رقم(333). 


\section{البصيرة: مجلة الاراسات الإسلامية \\ AL-BASHIRAH: JOURNAL OF ISLAMIC STUDIES \\ Vol. 2 No. 2 (2020): 168-185 \\ ISSN: $2807-2170$ \\ Website: https://journal.stiba.ac.id

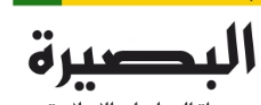 \\ مجلة الصراهات الإصلامية \\ AL-BASHIRAH

اتفق الأئمة الأربعة على أن النوم الكثير المستثقل يوجب الوضوء، وأن النوم القليل ليس بحدث، واتفقوا

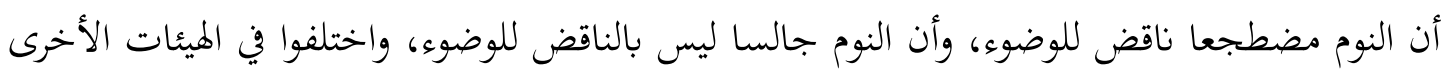
للنوم الناقض للوضوء.

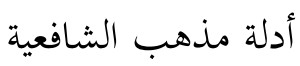

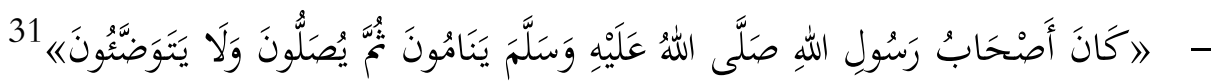

$$
\text { دل على استثناء هيئة الجلوس من هيئات النوم. }
$$

أدلة مذهب الحنابلة

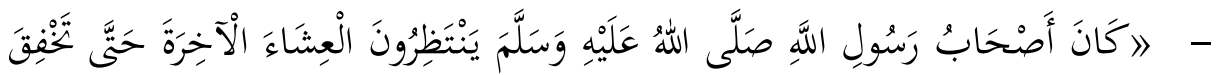

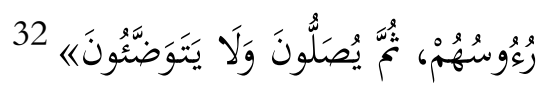

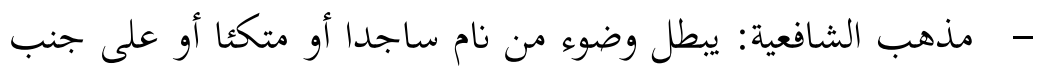

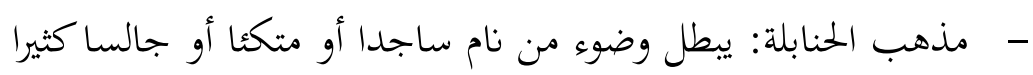

3 ) لمس النساء

اتفقوا على انتقاض وضوء من لمس امرأة بشهوة وخرج منه الشيء واختلف العلماء في إيباب الوضوء من

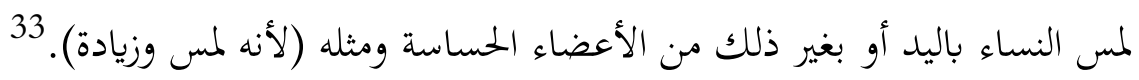

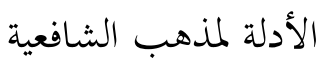

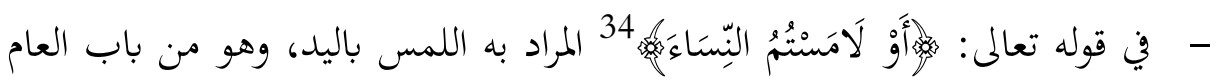
الذي أريد به العام فلا يشترط اللذة.

30 أبو الوليد محمد بن أحمد بن محمد بن أحمد بن رشد القرطبي الشهير بابن رشد الحفيد، بداية المجتهد وغاية المقتصد

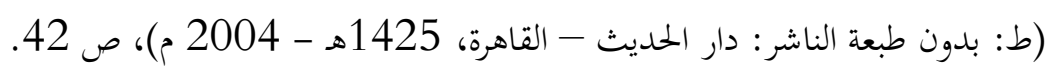

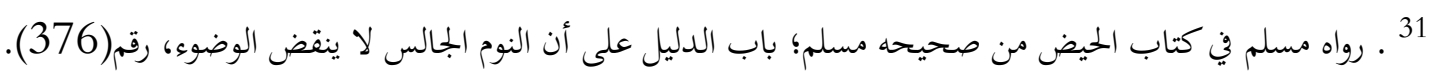

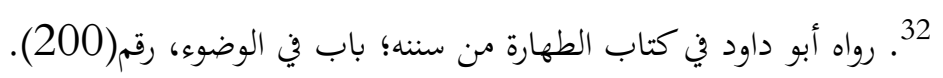

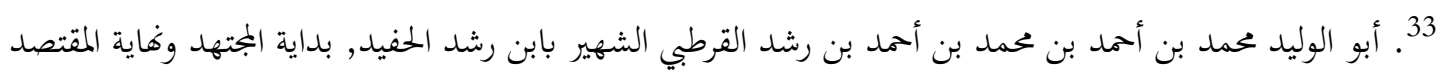

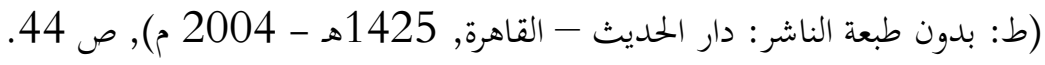

$$
\begin{aligned}
& \text { 34. سورة النساء: } 43
\end{aligned}
$$


البصيرة: مجلة الاراسات الإسلامية

AL-BASHIRAH: JOURNAL OF ISLAMIC STUDIES

Vol. 2 No. 2 (2020): 168-185

ISSN: $2807-2170$

Website: https://journal.stiba.ac.id

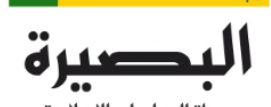

مجلة الدراهات الإصلامية

AL-BASHIRAH

- - اللمس يطلق الحقيقة على اللمس باليد، وبجازا على الجماع، وحيث تردد بينهما

فالأولى حمله على الحقيقة.

الأدلة لمذهب الحنابلة

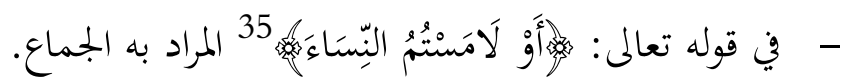

- أن النبي - صلى الله عليه وسلم - كان يلمس عائشة عند سجوده بيده وربما لمسته.

- -

ثمرة الخلاف

- مذهب الشافعية: ينتقض الوضوء مطلقا لمن لمس امرأة أوقبلها

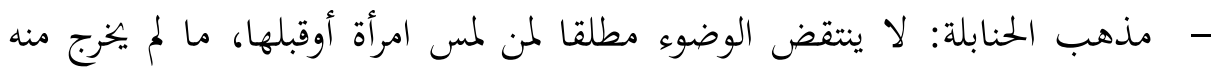

شيء.

4) أكل لخم الجزور

اتفق جمهور فقهاء الأمصار بعد الصدر الأول على عدم وجوب الوضوء من أكل ما مسته النار، وقد صح أنه من عمل الخلفاء الأربعة. واختلفوا هل الوضوء من أكل لحم الجزور داخل فيه أم لا؟37. أدلة مذهب الشافعية

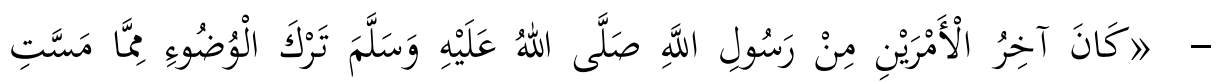
النَّارُ 《 الن

أدلة مذهب الحنابلة

43 35 43

36 ـ رواه أبو داود في كتاب الطهارة من سننه؛ باب الوضوء من القبلة، رقم(179)، والترمذي في أبواب الطهارة عن

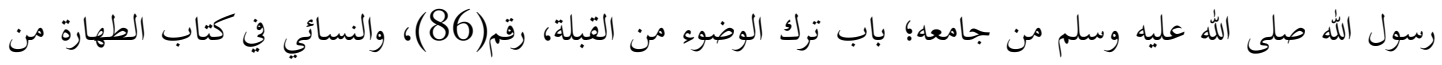

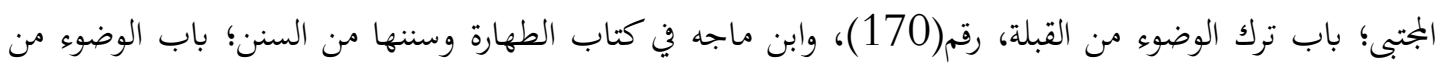

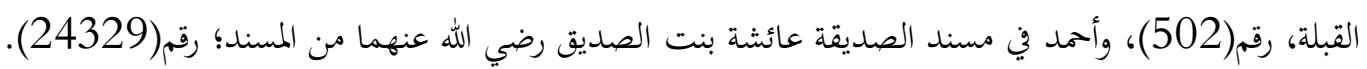

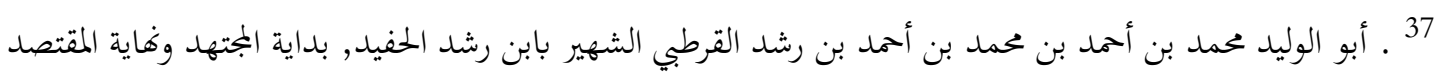

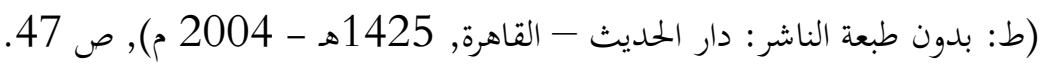

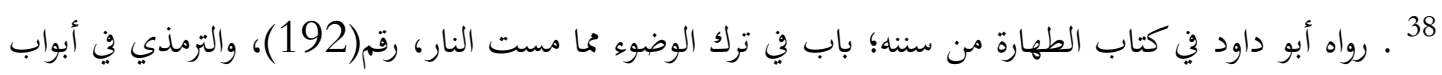

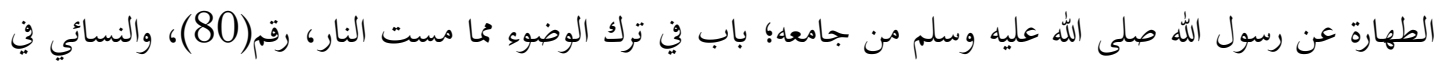
كتاب الطهارة من المجتى؛ باب ترك الوضوء مما غيرت النار، رقم( 
البصيرة: مجلة الاراسات الإسلامية

AL-BASHIRAH: JOURNAL OF ISLAMIC STUDIES

Vol. 2 No. 2 (2020): 168-185

ISSN: $2807-2170$

Website: https://journal.stiba.ac.id

البصيرة

مجلة الصراهات الإصلامية

AL-BASHIRAH

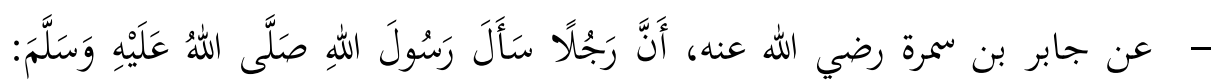

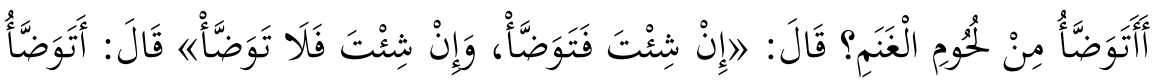

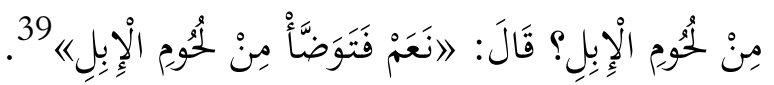

- - مذهب الشافعية: لا ينتقض الوضوء من أكل لحم الجزور

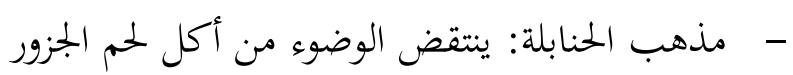

ترجيح الأقوال بينهما في نواقض الوضوء:

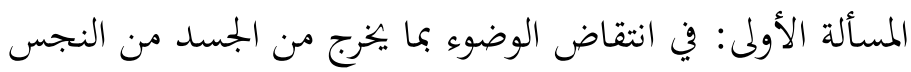

$$
\text { 1 ) مذهب الشافعية }
$$

لا ينتقض وضوء من قاء أو رعف، وينتقض إذا خرج من أحد سبيليه حصا أو نوها.

$$
\text { 2) مذهب الحنابلة }
$$

ينتقض وضوء من قاء أو رعف، ولا ينتقض إذا خرج من أحد سبيليه حصا أو نحوه.

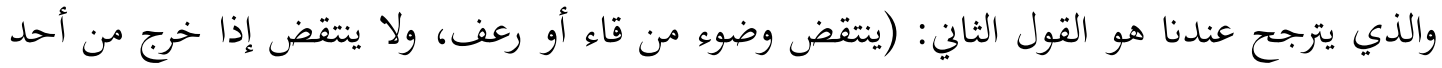

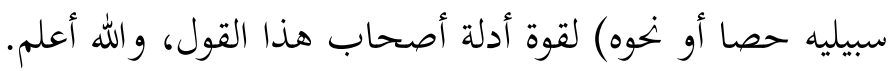
المسألة الثانية: في انتقاض الوضوء بالنوم جالسا لفوة اصحاب هدال

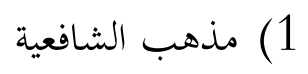

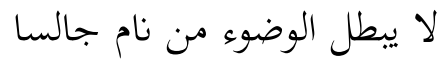

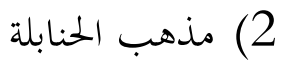

ييطل الوضوء من نام جالسا كثيرا ولا يبطل الوضوء من نام النوم اليسير

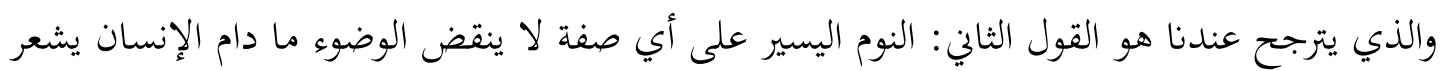

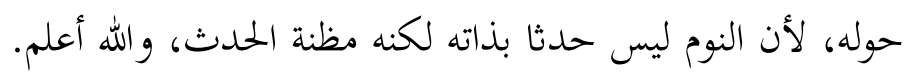

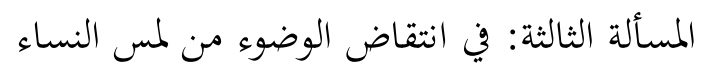

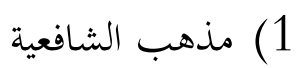

$$
39 \text {. رواه مسلم في كتاب الحيض من صحيحه؛ باب الوضوء من لحوم الإبل، رقم(360). }
$$


البصيرة: مجلة الاراسات الإسلامية

AL-BASHIRAH: JOURNAL OF ISLAMIC STUDIES

Vol. 2 No. 2 (2020): 168-185

ISSN: $2807-2170$

Website: https://journal.stiba.ac.id

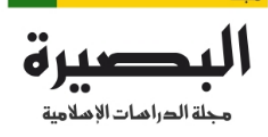

AL-BASHIRAH

$$
\text { 2) مذهب الحنقابلة الوضوء مطلقا لمن لمس امرأة أو قبلها }
$$

لا ينتقض الوضوء لمن لمس امرأة أو قبلها بغير لذة، وينقض الوضوء لمن لمس بلذة .

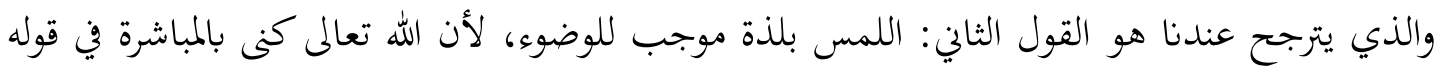

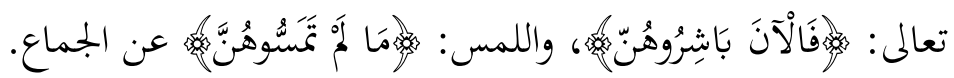

$$
\begin{aligned}
& \text { المسألة الرابعة: انتقاض الوضوء من أكل لحم الجزور } \\
& \text { 1) مذهب الشافعية } \\
& \text { لا ينتقض الوضوء من أكل لحم الجزور } \\
& \text { 2) مذهب الحنابلة } \\
& \text { ينتقض الوضوء من أكل لحم الجزور }
\end{aligned}
$$

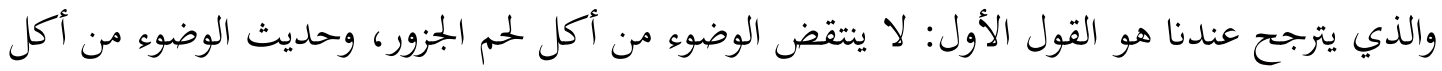

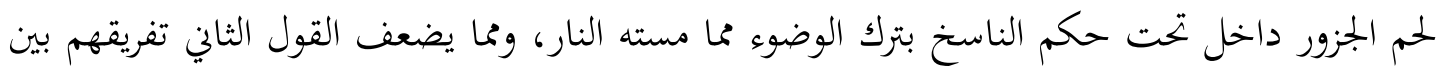

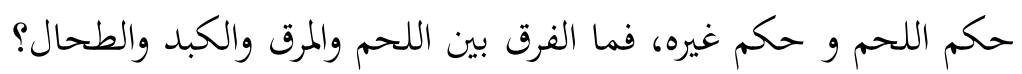

الخاتمة

أ. أ. نواقض الوضوء عند الشافعية والحنابلة:

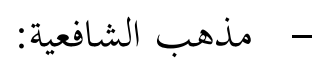

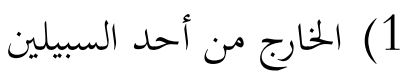

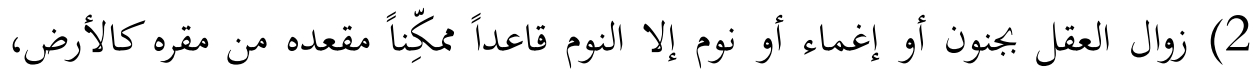

$$
\text { وظهر دابة سائرة، وإن كان مستنداً إلى شيء . }
$$

$$
\text { 3) التقاء بشرتي الرجل والمرأة ولو ميتة، عمداً أو سهواً. }
$$

$$
\begin{aligned}
& \text { 4) مس قبل الآدمي } \\
& \text { - مذهب الحنابلة: } \\
& \text { 1) الخارج من السبيلين. } \\
& \text { 2) خروج النجاسات من بقية البدن. } \\
& \text { 3) زوال العقل بجنون ونخوه . }
\end{aligned}
$$


البصيرة: مجلة الاراسات الإسلامية

AL-BASHIRAH: JOURNAL OF ISLAMIC STUDIES

Vol. 2 No. 2 (2020): 168-185

ISSN: $2807-2170$

Website: https://journal.stiba.ac.id

البصيرة

مجلة الصراهات الإصلامية

AL-BASHIRAH

$$
\text { 5) (5) غسل ذكر أو قبُّل أو دبُر آدمي من نفسه أو غيره . }
$$

7) موجبات الغسل كالتقاء الختانين وانتقال المني وإسلام الكافر الأصلي أو المرتد.

ب. أسباب الخلاف بين الشافعية والحنابلة في نواقض الوضوء.

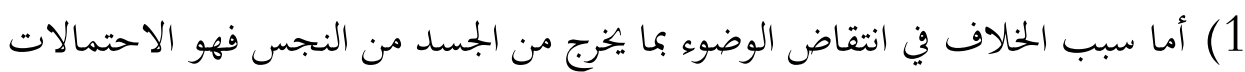

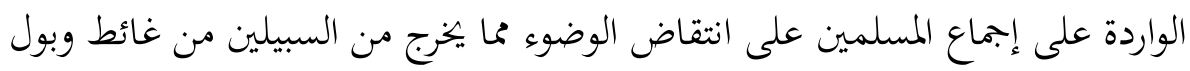

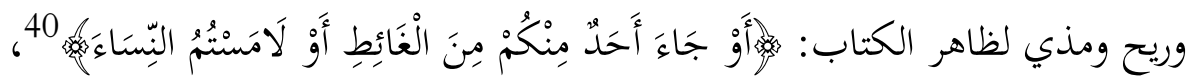

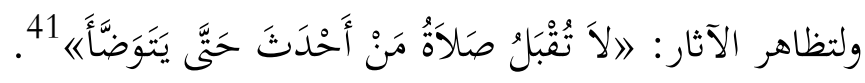

2) وأما سبب الخلاف في انتقاض الوضوء بالنوم جالسا فهو اختلاف في الهيئات الأخرى

$$
\text { للنوم الناقض للوضوء. }
$$

3) وأما سبب الخلاف في انتقاض الوضوء من لمس النساء هي اختلاف في المعنى قوله

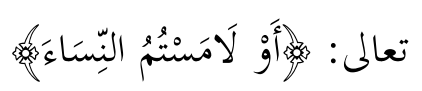

4) وأما سبب الخلاف في انتقاض الوضوء من أكل لحم الجزور هي اتفاق جمهور فقهاء

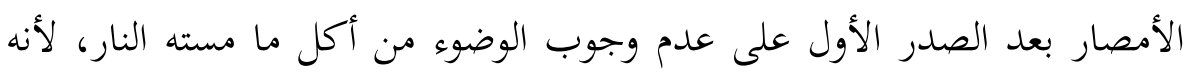

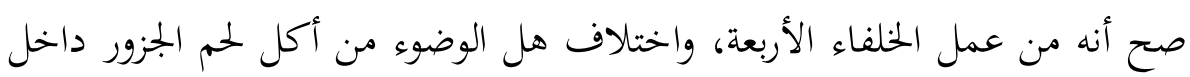

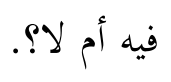

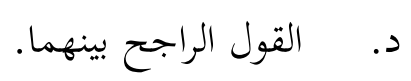

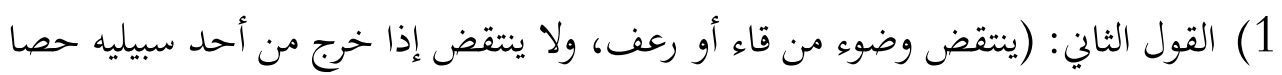

$$
\text { أو نوه) لقوة أدلة أصحاب هذا القول، و الله أعلم. }
$$

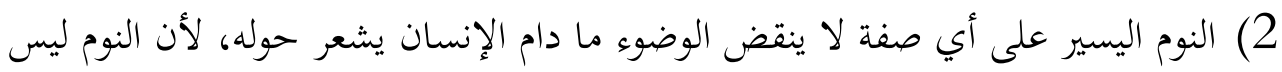

حدثا بذاته لكنه مظنة الحدث، و الله أعلم.

$$
40
$$

11. بواه البخاري في كتاب الوضوء من صحيحه؛ باب لا تقبل صلاة بغير طهور، رقم(135)، ومسلم في كتاب الطهارة

$$
\text { من صحيحه؛ باب وجوب الطهارة للصلاة، رقم(225). }
$$




\section{البصيرة: مجلة الدراسات الإسلامية \\ AL-BASHIRAH: JOURNAL OF ISLAMIC STUDIES \\ Vol. 2 No. 2 (2020): 168-185 \\ ISSN: $2807-2170$ \\ Website: https://journal.stiba.ac.id

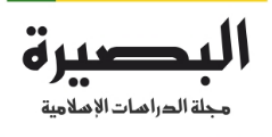 \\ AL-BASHIRAH \\ JOURNAL OF I}

$$
\begin{aligned}
& \text { 3) اللمس بلذة موجب للوضوء، لأن الله تعالى كنى بالمباشرة في قوله تعالى: هوَهَالْآنَ }
\end{aligned}
$$

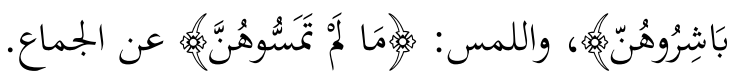

$$
\begin{aligned}
& \text { 4) لا ينتقض الوضوء من أكل لحم الجزور، وحديث الوضوء من أكل الحم الجزور داخل تحت } \\
& \text { حكم الناسخ بترك الوضوء مما مسته النار، ومما يضعف القول الثاني تفريقهم بين حكم } \\
& \text { اللحم وحكم غيره، فما الفرق بين اللحم والمرق والكبد والطحال؟ بكال }
\end{aligned}
$$

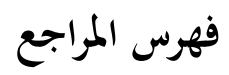

Abū al-Ḥusain, Muslim bin al-Ḥajjāj al-Qusyairī al-Naisābūrī. Șaḥ̄h Muslim, vol. II. AlṬab 'ah; I. Al-Qāhirah: Dār Ihyyā' al-Kutub al- 'Arabīah, dūna sanah

Abū Dāwūd, Sulaimān bin al-Asy'aś al-Azdī al-Sijistānī. Sunan Abī Dāwūed, vol. III. AlṬab ah; I. Dār al-Risālah al- 'Ālamīah, 2009

Al-Bukhārī, Muḥammad bin Ismā īl. Șaḥịh al-Bukhārī. Al-Qāhirah: dār al-ḥadis̀, 2004 Al-Qur'ān al-Karīm

Al-Syāfi '̄i, Abū 'Abdillah Muḥammad bin Idris. Al-Umm, vol. I. Dūna țab 'ah

Al-Tirmiżī, Muhammad bin 'Īsā bin Saurah bin Mūsā bin al-Ḍhhạ̄e. Sunan al-Tirmiżī, vol. IV. Al-Ṭab ah; II. Miṣr: Syarikah Maktabah wa Maṭba ah Mușțafā al-Bābī al-Halabī, 1975

Al-Zuhailī, Wahbah bin Mușțafā. Al-Fiqh al-Islāmī wa Adillatuh, vol.VII. Al-Ṭab'ah: IV. Sūrīah: Dār al-Fikr, Dūna sanah

Ibn Mājah, Abū 'Abdillāh Muḥammad bin Yazīd al-Qazwin̄i. Sunan Ibn Mãjah. Al-Ṭab 'ah; I. Dār Ihyā al-Kutub al-'Arabīah, dūna sanah

Ibn Qudāmah al-Maqdisī, Abū Muḥammad 'Abdullāh bin Aḥmad bin Muḥammad. Al-Mugnī lī Ibn Qudāmah, vol. II. Al-Ṭab'ah: I. Maktabah al-Qāhirah, 1968

Ibn Rusyd al-Qurțub̄̄, Abū al-Walid Muhammad bin Ahmad. Bidāyah al-Mujtahid wa Nihāyah al-Muqtaṣid, vol. II. Al-Ṭab'ah; I. Al-Qāhirah: Dār al-Hadīṣ, 2004

Malik bin Anas. Al-Muwațta'. Al-Ṭab 'ah; I. Bīrūt: Dār Șādir, 1993

Muștafāà al-Khān wa Zumalā'uh. Al-Fiqh al-Manhajī 'alā Mażhab al-Imām al-Syāfi ì , vol. I. Dūna țab'ah 